\title{
KOMPONEN KIMIA DAN FISIK ABU SEKAM PADI SEBAGAI SCM UNTUK PEMBUATAN KOMPOSIT SEMEN
}

\author{
Chemical and Physical Component of Rice Husk Ash as SCM for Cement Composite Manufacture
}

Bakri

\begin{abstract}
This research aimed to determine chemical and physical component of rice husk ash as supplementing cement material to manufacture cement composite products. Charcoal of rice husk ash obtained by burning rice husk conventionally in kiln drum and burned again in furnace 1400 Barnsted Thermolyne Type at temperature $600^{\circ} \mathrm{C}$ for 2 hours. Analysis of chemical and physical component refer to SNI 152049-2004. Major chemical compound of rice husk ash was $72.28 \%$ of silica and 21.43 of LOI. Density of rice husk ash was $760 \mathrm{~kg} / \mathrm{m}^{3}$.
\end{abstract}

Key words: SCM, rice husk ash, chemical and physical component, cemet composite.

\section{PENDAHULUAN}

Sekam padi merupakan bahan berlignoselulosa seperti biomassa lainnya namun mengandung silika yang tinggi. Kandungan kimia sekam padi terdiri atas $50 \%$ selulosa, $25-30 \%$ lignin, dan $15-20 \%$ silika (Ismail and Waliuddin, 1996). Sekam padi saat ini telah dikembangkan sebagai bahan baku untuk menghasilkan abu yang dikenal di dunia sebagai RHA (rice husk ask). Abu sekam padi yang dihasilkan dari pembakaran sekam padi pada suhu $400^{\circ}-500^{\circ} \mathrm{C}$ akan menjadi silika amorphous dan pada suhu lebih besar dari $1.000^{\circ} \mathrm{C}$ akan menjadi silika kristalin.

Silika amorphous yang dihasilkan dari abu sekam padi diduga sebagai sumber penting untuk menghasilkan silikon murni, karbid silikon, dan tepung nitrid silikon (Katsuki et al., 2005). Konversi sekam padi menjadi abu silika setelah mengalami proses karbonisasi juga merupakan sumber pozzolan potensil sebagai SCM (Supplementary Cementitious Material). Abu sekam padi memiliki aktivitas pozzolanic yang sangat tinggi sehingga lebih unggul dari SCM lainnya seperti fly ash, slag, dan silica fume.

Beberapa hasil ikutan industri dan pertanian seperti slag, fly ash, dan rice husk ash (abu sekam padi) ternyata merupakan polutan potensil yang dapat digunakan sebagai bahan subtitusi atau bahan tambahan semen. Penggunaan bahan pengganti sebagian semen (SCM) melalui komposisi campuran yang inovatif akan mengurangi jumlah semen yang digunakan sehingga secara ekologis dapat mengurangi emisi gas-gas rumah kaca dan penggunaan konsumsi energi fosil bumi pada industri semen. Pembakaran sekam padi dengan menggunakan metode konvensional seperti fluidised bed combustors menghasilkan emisi CO antara 200 $2000 \mathrm{mg} / \mathrm{Nm}^{3}$ dan emisi $\mathrm{NO}_{x}$ antara $200-300$ $\mathrm{mg} / \mathrm{Nm}^{3}$ (Armesto et al., 2002). Metode pembakaran sekam padi yang dikembangkan oleh COGEN-AIT mampu mengurangi potensi emisi $\mathrm{CO}_{2}$ sebesar 14.762 ton, $\mathrm{CH}_{4}$ sebesar 74 ton, dan $\mathrm{NO}_{2}$ sebesar 0,16 ton pertahun dari pembakaran sekam padi sebesar 34.919 ton pertahun (Mathias, 2000).

Penggunaan abu sekam padi dengan kombinasi campuran yang sesuai pada semen akan menghasilkan semen yang lebih baik (Singh et al., 2002). Abu sekam padi telah digunakan sebagai bahan pozzolan reaktif yang sangat tinggi untuk meningkatkan mikrostruktur pada daerah transisi interfase antara pasta semen dan agregat beton yang memiliki kekuatan tinggi. Penggunaan abu sekam padi pada komposit semen dapat memberikan beberapa keuntungan seperti meningkatkan kekuatan dan ketahanan, mengurangi biaya bahan, mengurangi dampak lingkungan limbah bahan, dan mengurangi emisi karbon dioksida (Bui et al., 2005).

Penggantian sebagian semen oleh abu sekam padi sebesar $40 \%$ dalam pembuatan mortar dapat menghasilkan kekuatan yang baik dan ketahanan terhadap sulfat sehingga akan mengurangi semen yang digunakan, mengurangi emisi gas rumah 
kaca, dan meningkatkan masa pakai mortar (Chindaprasirt et al., 2007). Walaupun Sarawasthy and Song (2007) menyarankan penggunaan abu sekam padi sebesar $25 \%$ untuk membuat komposit semen tetapi penggunaan abu sekam padi sampai $30 \%$ sebagai pengganti sebagian semen masih dapat mengurangi penetrasi klorida, mengurangi permeabilitas, meningkatkan kekuatan, dan meningkatkan sifat anti karat komposit semen.

Chindaprasirt and Rukzon (2008) menemukan bahwa mortar yang menggunakan RHA lebih tahan terhadap penetrasi klorida dibandingkan mortar yang menggunakan palm oil fuel ash dan fly ash. Penggunaan abu sekam padi sebagai SCM pada jembatan, bangunan dermaga, dan bangunan pembangkit tenaga nuklir akan memiliki kekuatan tinggi dan permeabilitas rendah karena abu sekam padi dapat meningkatkan reaksi pozzolan untuk pembentukan kalsium silikat hidrat (Dakroury and Gasser, 2008).

Penggunaan $10 \%$ abu sekam padi dapat meningkatkan kekuatan tekan concrete yang menggunakan agregat pasir setelah 28 hari curing period sebesar 99,45 $\mathrm{MPa}$ dan kekuatan tarik pisah sebesar $7 \mathrm{MPa}$ (Silva et al., 2008). Pembuatan sandcrete block yang dilakukan oleh Oyetola and Abdullahi (2006) menunjukkan bahwa penggantian optimum oleh abu sekam padi pada semen adalah $20 \%$ untuk menghasilkan kekuatan tekan sebesar 36,5 MPa setelah 28 hari curing period. Penggantian $20 \%$ abu sekam padi pada semen untuk mortar yang menggunakan agregat pasir menghasilkan kekuatan tekan mortar sebesar $54 \mathrm{MPa}$ setelah 28 hari curing period (Chindaprasirt et al., 2007). Hasil-hasil penelitian ini membuktikan bahwa penggunaan abu sekam padi sebagai pengganti sebagian semen efektif menaikkan kekuatan tekan komposit semen pada rasio abu sekam padi terhadap semen (abu sekam padi/semen + abu sekam padi) sebesar $20 \%$ pada agregat batuan tidak reaktif. DTI (2003) menjelaskan bahwa penggunaan abu sekam padi/semen sampai $35 \%$ masih dapat dilakukan untuk mencapai kekuatan tekan maksimum sedangkan penggunaan abu sekam padi/semen + abu sekam padi sebesar $50 \%$ masih cukup efektif tetapi kekuatan komposit semen akan berkurang setelah 28 hari curing period. Ganesan et al. (2008) mengemukakan bahwa penggantian semen sebesar $30 \%$ oleh abu sekam padi tidak menghasilkan efek menurun pada kekuatan mortar.

\section{METODE PENELITIAN}

Bahan penelitian terdiri atas sekam padi, air suling, dan beberapa reaktan. Instrumen penelitian terdiri atas gelas ukur, tabung reaksi, timbangan digital, thermometer, hygrometer, furnace tipe 1400 Barnsted Thermolyne, caliper, baskom, ember, kantung plastik, dandang aluminium, drum pembakaran, ayakan, blender, tanur, dan komputer. Penelitian dilaksanakan pada Oktober Nopember 2008 di Laboraturium IImu Kayu dan Diversifikasi Produk Hasil Hutan Universitas Hasanuddin.

Sekam padi yang telah disiapkan dicuci dengan air untuk memisahkan kotoran yang melekat dan dikeringkan selama beberapa hari sampai mencapai keadaan kering udara. Pembakaran sekam padi untuk menghasilkan abu dilakukan menurut metode yang dilakukan oleh Silva et al. (2008), Harsono (2002), dan Ganesan et al. (2008) dengan melakukan beberapa penyesuaian. Sekam padi dibakar dalam drum pada suhu $\pm 300^{\circ} \mathrm{C}$ selama 60 menit untuk mendapatkan arang sekam padi. Arang sekam padi kemudian didinginkan selama 24 jam kemudian dibakar pada furnace tipe 1400 Barnsted Thermolyne pada suhu $600^{\circ} \mathrm{C}$ selama 2 jam. Abu sekam padi yang berasal dari pembakaran furnace kemudian didinginkan selama 24 jam dan kemudian digiling dalam blender selama 2 menit. Abu sekam padi kemudian diayak pada ayakan 325 mesh dan disimpan dalam kantong plastik yang tertutup sebelum dianalisis. Analisis fisik dan kimia bahan dilakukan dengan mengadopsi SNI 15-2049-2004 (BSN, 2004)

\section{HASIL DAN PEMBAHASAN}

Komponen kimia dan fisik abu sekam padi yang dibuat dalam penelitian ini ditunjukkan pada Tabel 1. Komponen kimia yang paling dominan terkandung pada abu sekam padi yang dihasilkan yaitu $\mathrm{SiO}_{2}$ sebesar $72,28 \%$ dan senyawa hilang pijar sebesar 21,43 \%.. Sedangkan persentase kandungan senyawa $\mathrm{CaO}, \mathrm{Al}_{2} \mathrm{O}_{3}$, dan $\mathrm{Fe}_{2} \mathrm{O}_{3}$, tergolong sangat rendah yaitu masing-masing sebesar $0,65 \%, 0,37 \%$, dan $0,32 \%$. 
Table 1. Chemical and Physical Components of Rice Husk Ash

\begin{tabular}{|c|c|c|}
\hline \multicolumn{2}{|c|}{ Chemicals } & Physics \\
\hline $\mathrm{SiO}_{2}(\%$ berat $)$ & 72,28 & \\
\hline $\mathrm{Al}_{2} \mathrm{O}_{3}(\%$ berat $)$ & 0,37 & Kerapatan gembur \\
\hline $\mathrm{Fe}_{2} \mathrm{O}_{3}(\%$ berat $)$ & 0,32 & Lolos ayakan $45 \mu \mathrm{m}$ \\
\hline $\mathrm{CaO}$ (\% berat) & 0,65 & Tidak lolos ayakan $45 \mu \mathrm{m}=25 \%$ \\
\hline Hilang pijar ( $\%$ berat) & 21,43 & \\
\hline
\end{tabular}

Perhitungan pembentukan tipe mineral atau fasa senyawa abu sekam padi pada Tabel 2 menunjukkan bahwa abu sekam padi yang dibuat tidak memiliki fasa senyawa alite (C3S) dan balite (C2S) sedangkan aluminate (C3A), dan ferrite (C4AF) sangat rendah yaitu masing-masing sebesar $0,44 \%$ dan 0,98 \%. Karena abu sekam padi tidak memiliki fasa senyawa C3S dan C2S maka abu sekam padi tidak dapat digolongkan sebagai matriks dalam pengertian semen. Namun demikian karena abu sekam padi memiliki kandungan $\mathrm{SiO}_{2}$ yang tinggi maka abu sekam padi dapat dijadikan sebagai pengganti sebagian matriks semen.

Matriks semen hidrolik jika bereaksi dengan air akan menghasilkan kalsium silikat hidrat (CSH) primer dan kalsium hidroksida $(\mathrm{CH})$. Pembentukan $\mathrm{CSH}$ dan $\mathrm{CH}$ dalam proses hidrasi dikendalikan oleh hidrasi $\mathrm{C}_{3} \mathrm{~S}$ dan $\mathrm{C} 2 \mathrm{~S}$ dalam semen. Hidrasi $\mathrm{C}_{3} \mathrm{~S}$ dan $\mathrm{C}_{2} \mathrm{~S}$ menghasilkan $\mathrm{CSH}$ dan $\mathrm{CH}$ yang berbeda. Jumlah $\mathrm{CH}$ yang dihasilkan dari proses hidrasi $\mathrm{C}_{3} \mathrm{~S} 3$ kali lebih banyak dari $\mathrm{C}_{2} \mathrm{~S}$. $\mathrm{CH}$ yang terbentuk pada proses hidrasi berbentuk hexagonal dan menempati $20-25 \%$ volume pasta semen, tetapi tidak memberikan konstribusi kekuatan pada semen. Sedangkan $\mathrm{CSH}$ merupakan gel kaku yang tersusun oleh partikelpartikel sangat kecil dengan susunan lapisan yang cenderung membentuk formasi agregat yang akan memberikan kekuatan pada semen.

Penggantian sebagian semen oleh abu sekam padi akan menghasilkan reaksi antara $\mathrm{CH}$ dan silika abu sekam padi yang menyebabkan terbentuknya $\mathrm{CSH}$ sekunder. Jumlah $\mathrm{CSH}$ sekunder yang terbentuk tergantung pada proporsi antara silika yang dikandung oleh abu sekam padi dan $\mathrm{CH}$ yang dihasilkan dari reaksi $\mathrm{C} 3 \mathrm{~S}$ atau $\mathrm{C} 2 \mathrm{~S}$ dan air. Persentase silika yang dikandung oleh abu sekam padi yang dibuat dalam penelitian ini sebesar 72, $28 \%$ lebih kecil dari persentase silika abu sekam padi yang dibuat pada skala industri. Persentase silika abu sekam padi yang dibuat pada skala industri umumnya di atas $90 \%$. Penelitian yang dilakukan oleh Gastaldini et al. (2007), Silva et al. (2008), Chindaprasirt et al. (2007), dan Oyetola and Abdullahi (2006) menunjukkan bahwa penggunaan abu sekam padi yang memiliki kandungan silika di atas $85 \%$ sebagai pengganti sebagian semen sampai sebesar $30 \%$ dapat meningkatkan kekuatan komposit semen yang dibuat.

Table 2. Content Percentage of $C_{3} S, C_{2} S, C_{3} A$, and $C_{4} A F$ of Rice Hausk Ash $\left.{ }^{*}\right)$

\begin{tabular}{|c|c|c|c|c|}
\hline $\begin{array}{l}\text { Common } \\
\text { Notation }\end{array}$ & $\begin{array}{l}\text { Chemical } \\
\text { Formula }\end{array}$ & $\begin{array}{l}\text { Mineral } \\
\text { Name }\end{array}$ & Calculation of Content Percentage & $\begin{array}{l}\text { Value of Content } \\
\text { (\%) }\end{array}$ \\
\hline 1. $\mathrm{C}_{3} \mathrm{~S}$ & $3 \mathrm{CaO} . \mathrm{SiO}_{2}$ & Alite & $\begin{array}{l}(4,071 \times \% \mathrm{CaO})-(7,600 \times \% \\
\left.\mathrm{SiO}_{2}\right)-\left(6,718 \times \% \mathrm{Al}_{2} \mathrm{O}_{3}\right)-(1,430 \\
\left.\times \% \mathrm{Fe}_{2} \mathrm{O}_{3}\right)-\left(2,852 \times \% \mathrm{SO}_{3}\right)\end{array}$ & $\begin{array}{c}\text { nilai persentase } \\
\text { negatif }\end{array}$ \\
\hline 2. $\mathrm{C}_{2} \mathrm{~S}$ & $2 \mathrm{CaO} \cdot \mathrm{SiO}_{2}$ & Balite & $\begin{array}{l}\left(2,867 \times \% \mathrm{SiO}_{2}\right)-(0,7544 \times \% \\
\text { C3S })\end{array}$ & $\begin{array}{l}\text { nilai persentase } \\
\text { negatif }\end{array}$ \\
\hline 3. $\mathrm{C}_{3} \mathrm{~A}$ & $3 \mathrm{CaO} \cdot \mathrm{Al}_{2} \mathrm{O}_{3}$ & Aluminate & $\begin{array}{l}\left(2,650 \times \% \mathrm{Al}_{2} \mathrm{O}_{3}\right)-(1,692 \times \% \\
\left.\mathrm{Fe}_{2} \mathrm{O}_{3}\right)\end{array}$ & 0,44 \\
\hline 4. $\mathrm{C}_{4} \mathrm{AF}$ & $4 \mathrm{CaO} \cdot \mathrm{Al} 2 \mathrm{O} 3 . \mathrm{Fe}_{2} \mathrm{O}_{3}$ & Ferrite & $\left(3,043 \times \% \mathrm{Fe}_{2} \mathrm{O}_{3}\right)$ & 0,98 \\
\hline
\end{tabular}


Reaksi abu sekam padi dengan $\mathrm{CH}$ mengakibatkan jumlah $\mathrm{CH}$ akan berkurang, $\mathrm{CSH}$ bertambah, dan permeabilitas berkurang (Chatveera and Lertwattanaruk, 2008). Pembentukan $\mathrm{CSH}$ sekunder yang semakin banyak dari reaksi abu sekam padi dan $\mathrm{CH}$ akan mengurangi jumlah senyawa $\mathrm{CH}$ sehingga menambah ketahanan pasta semen terhadap serangan kimia dari luar. Jumlah $\mathrm{CH}$ yang berkurang dapat menurunkan alkalinitas pasta semen sehingga mengurangi reaksi senyawa asam atau basa. Senyawa asam atau basa dapat dapat bereaksi dengan $\mathrm{CH}$ yang dapat merusak atau melunakkan CSH. Jika permeabilitas pasta semen tinggi maka air dan senyawa luar lainnya akan mudah masuk ke dalam pasta semen. Pembentukan CSH sekunder dapat mengurangi permeabilitas pasta semen sehingga menghalangi masuknya zat cair ke dalam pasta semen.

Senyawa hilang pijar abu sekam padi yang dibuat sebesar 21,43\% dapat dijadikan petunjuk bahwa jumlah karbon terikat pada abu sekam padi cukup besar. Karbon terikat ini merupakan unsur karbon dari senyawa biomassa sekam padi yang tidak menguap pada saat pembakaran. Persentase jumlah karbon terikat yang besar ini akan mengurangi persentase kandungan silika pada abu sekam padi. Penggunaan abu sekam padi dengan kandungan karbon yang banyak sebagai pengganti sebagian semen dalam pembuatan komposit semen akan mempengaruhi sifat fisik dan mekanik komposit semen. Beberapa penelitian telah dilakukan pada penggunaan karbon bergeometri nanotube yang ditemukan pada tahun 1991 untuk meningkatkan kekuatan komposit semen tetapi dalam jumlah yang sangat kecil yaitu kurang dari 1 $\%$ berat semen. Penggunaan karbon nanotube sebesar $0,5 \%$ berat semen dapat meningkatkan kuat tekan sebesar $25 \%$ dan kuat patah sebesar $19 \%$ (Li et al., 2005). Yu and Kwon (2009) menggunakan karbon nanotube sebesar $0,1 \%$ dari berat semen tetapi tidak menunjukkan peningkatan kekuatan mekanis yang berarti pada komposit semen. Walaupun Yu and Kwon (2009) menyarankan untuk menggunakan karbon nanotube pada persentase yang lebih tinggi tetapi sebelumnya Makar and Beaudoin (2003) telah mengemukakan bahwa penggunaan karbon nanotube pada persentase $2-10 \%$ belum tentu dapat menghasilkan sifat mekanis yang baik. Kandungan senyawa hilang pijar yang cukup besar pada abu sekam padi dapat menyebabkan berkurangnya reaktifitas silika terhadap $\mathrm{CH}$ pada proses hidrasi.

Keadaan fisik abu sekam padi pada Tabel 1 menunjukkan bahwa kerapatan gembur abu sekam padi tergolong sedang yaitu sebesar $760 \mathrm{~kg} / \mathrm{m}^{3}$. Kerapatan gembur merupakan kerapatan partikel butiran suatu bahan pada volume tertentu yang dipadatkan tetapi masih memiliki rongga di antara partikel-partikel butiran. Nilai kerapatan ini dipengaruhi oleh kerapatan senyawa kimia yang dominan terdapat pada bahan tersebut dan volume rongga yang terdapat pada volume bahan tertentu. Tabel 1 menunjukkan bahwa senyawa kimia dominan pada abu sekam padi yaitu $\mathrm{SiO}_{2}$ tergolong memiliki kerapatan padat sedang. Walaupun kalsium oksida $(\mathrm{CaO})$ memiliki kerapatan padat tinggi tetapi senyawa ini memiliki persentase sangat sedikit pada abu sekam padi. Kerapatan padat $\mathrm{SiO}_{2}$ adalah sebesar $2.641 \mathrm{~kg} / \mathrm{m}^{3}$ dan kerapatan padat $\mathrm{CaO}$ adalah sebesar 3.341 $\mathrm{kg} / \mathrm{m}^{3}$ (Balonis and Glasser, 2009).

Kerapatan abu sekam padi sebesar $760 \mathrm{~kg} / \mathrm{m}^{3}$ jauh lebih rendah dibandingkan dengan kerapatan semen Portland tipe I yaitu sebesar $1.250 \mathrm{~kg} / \mathrm{m}^{3}$. Semakin banyak jumlah persentase abu sekam padi yang digunakan untuk mengganti semen maka jumlah semen semakin berkurang sehingga kerapatan matriks secara keseluruhan akan lebih rendah dari kerapatan semen. Komposit semen yang dibuat dengan menggunakan abu sekam padi sebagai pengganti sebagian semen akan mengurangi kerapatan komposit semen namun dapat meningkatkan kekuatan komposit semen.

Hasil penyaringan dengan menggunakan ayakan berukuran $45 \mu \mathrm{m}$ atau 325 mesh menunjukkan bahwa persentase lolos ayakan abu sekam padi adalah $75 \%$. Walaupun beberapa hasil analisis menunjukkan bahwa ukuran butiran partikel abu sekam padi lebih kecil dari semen namun pada Tabel 1 menunjukkan bahwa jumlah butiran partikel yang memiliki ukuran lebih besar dari $45 \mu \mathrm{m}$ atau tidak lolos ayakan $45 \mu \mathrm{m}$ cukup banyak terdapat pada abu sekam padi yaitu sebesar $25 \%$. Hal ini disebabkan karena abu sekam padi yang dibuat masih mengandung karbon terikat dalam jumlah yang cukup besar dalam senyawa hilang pijar berbentuk partikel arang halus.

Abu sekam padi yang memiliki ukuran butiran partikel yang tidak lolos ayakan $45 \mu \mathrm{m}$ akan memiliki bentuk yang tidak teratur dan porositas internalnya sangat tinggi. Penggilingan abu hasilhasil pertanian menjadi partikel yang halus akan 
memecah struktur internal partikel abu sekam padi sehingga bentuk partikelnya menjadi lebih teratur dan porositas internalnya bisa berkurang. Jika sebagian besar senyawa abu sekam padi (di atas $90 \%)$ terdiri atas silika $\left(\mathrm{SiO}_{2}\right)$ maka persentase lolos ayakan ukuran $45 \mu \mathrm{m}$ akan menjadi lebih tinggi.

Partikel abu sekam padi yang sangat halus memiliki arti penting dalam proses hidrasi semen. Laju hidrasi akan meningkat dengan berkurangnya ukuran partikel sehingga dapat meningkatkan kekuatan pasta semen (Dermibas, 2004). ). Selain itu abu sekam padi yang memiliki ukuran partikel lebih kecil dari semen dapat berfungsi sebagai mikrofiller untuk meningkatkan kerapatan komposit semen (Nehdi, 2004). Abu sekam padi yang memiliki luas permukaan spesifik silika amorf 40 $60 \mathrm{~m}^{2} / \mathrm{g}$ akan bereaksi dengan $\mathrm{Ca}(\mathrm{OH})_{2}$ dengan adanya air dan membentuk CSH pada suhu $40^{\circ} \mathrm{C}$ (Yu et al., 1999). Abu sekam padi yang memiliki ukuran partikel yang sangat rendah yaitu kurang dari $11 \mu \mathrm{m}$ merupakan bahan yang sangat reaktif dan dapat digunakan untuk menghasilkan beton yang memiliki kekuatan tekan sebesar $85 \mathrm{MPa}$ setelah 28 hari curing periode pada abu sekam padi/semen + abu sekam padi sebesar $30 \%$ (Sata et al., 2007). Pengaruh abu sekam padi terhadap berbagai parameter yang berhubungan rheology seperti viskositas, plastisitas, dan elastisitas tergantung dari distribusi ukuran partikel, luas permukaan spesifik, bentuk dan sifat permukaan abu sekam padi. Abu sekam padi ditemukan sebagai bahan yang paling sesuai sifat rheologynya yaitu memiliki viskositas plastis yang sedang dan menghasilkan tegangan yang rendah (Laskar and Talukdar, 2008).

\section{KESIMPULAN}

1. Persentase silika abu sekam padi yang dihasilkan dalam penelitian ini yaitu sebesar $72,28 \%$ lebih rendah dari yang dihasilkan pada skala industri yaitu di atas $90 \%$.

2. Kerapatan gembur abu sekam padi sebesar $760 \mathrm{~kg} / \mathrm{m}^{3}$ akan menghasilkan kerapatan komposit semen yang lebih rendah.

3. Walaupun abu sekam padi tidak dapat digolongkan sebagai matriks semen karena tidak Mengandung C3S dan C2S tetapi dapat digunakan sebagai pengganti sebagian semen untuk menghasilkan $\mathrm{CSH}$ sekunder dalam pembuatan komposit semen.

\section{SARAN}

Pembakaran arang sekam padi pada suhu $600{ }^{\circ} \mathrm{C}$ selama 3 sampai 4 jam di furnace tipe 1400 Barnsted perlu dicoba untuk mendapatkan persentase silika abu sekam padi di atas $90 \%$. Metode pengarangan sekam padi dalam drum perlu dimodifikasi untuk mendapatkan pengaturan distribusi panas yang seragam selama proses pengarangan sekam padi.

\section{DAFTAR PUSTAKA}

Armesto, L., Bahillo, A., Veijonen, K. Cabanillas, A., and Otero, J. 2002. Combustion Behaviour of Rice Husk in a Bubbling Fluidised Bed. Biomass and Bioenergy. 23: 171 - 179.

Balonis, M. and Glasser, F.P. 2009. The Density of Cement Phases. Department of Chemistry, University of Aberdeen. Aberdeen, Scotland, UK.

BSN. 2004. Semen Portland Komposit. SNI 15-70642004. Badan Standardisasi Nasional, Jakarta.

Bui, D. D., Hu, J. and Stroeven, P. 2005. Particle Size Effect on the Strength of Rice Husk Ash Blended Gap-Graded Portland Cement Concrete. Cement \& Concrete Composites. 27: 357-366.

Chatveera, B. and Lertwattanaruk, P. 2008. Evaluation of Sulfate Resistance of Cement Mortars Containing Black Rice Husk Ash. Journal of Environmental Management. 30: 1-7

Chindaprasirt, P., Kanchanda, P., Sathonsaowaphak, A., and Cao, H.T. 2007. Sulfate Resistance of Blended Cements Containing Fly Ash and Rice Husk Ash. Construction and Building Materials Journal. 21: $1356-1361$

Chindaprasirt, P. and Rukzon, S. 2008. Strength, porosity and corrosion resistance of ternary blend Portland cement, rice husk ash and fly ash mortar. Construction and Building Materials. 22: 1601-1606.

Dakroury, A. El. and Gasser, M. S. 2008. Rice Husk Ash (RHA) as Cement Admixture for Immobilization of Liquid Radioactive Waste at Different Temperatures. Journal of Nuclear Materials. 381: 271- 277.

Demirbas, A. 2004. A discussion of the paper "Performance of Rice Husk Ash Produced Using a New Technology as a Mineral Admixture in Concrete". Cement and Concrete Research. 34: 1269. 
DTI. 2003. Rice Husk Ash Market Study. DTI/Pub URN 03/668. United Kingdom: Brozeoak Ltd (Contractor).

Ganesan, K., Rajagopal, K., and Thangavel, K. 2008. Rice husk ash blended cement: Assessment of Optimal Level of Replacement for Strength and Permeability Properties of Concrete. Construction and Building Materials. 22 (8): 1675 $-1683$.

Gastaldini, A. L. G., Isaja, G. C., Gomes, N. S., and Sperb, J. E. K. 2007. Chloride Penetration and Carbonation in Concrete with Rice Husk Ash and Chemical Activators. Cement \& Concrete Composites. 29: $176-180$.

Harsono, H. 2002. Pembuatan Silika Amorf dari Limbah Sekam Padi. Jurnal IImu Dasar. 3 (2): 98 $-103$.

Ismail, M. S. and Waliuddin, A. M. 1996. Effect of Rice Husk Ash on High Strength Concrete. Construction and Building Materials. 10 (1): 521 $-526$

Katsuki, H., Furuta, S., Watari, T. and Komarneni, S. 2005. ZSM-5 zeolite/porous carbon composite: Conventional- and Microwave-Hydrothermal Synthesis from Carbonized Rice Husk. Microporous and Mesoporous Materials. 86: 145 $-151$.

Laskar, A. I. and Talukdar, S. 2008. Rheological Behavior of High Performance Cconcrete with Mineral Admixtures and Their Blending. Construction and Building Materials. 22: 2345 2354..

Li, G. Y., Wang, P. M., and Zhao, X. 2005. Mechanical Behavior and Microstructure of Cement Composites Incorporating Surfacetreated multi-walled Carbon Nanotubes . Carbon. 43: $1239-45$

Makar, J.M. and Beaudoin, J.J. 2003. Carbon Nanotubes and Their Application in the Construction Industry. Proceeding of 1 st International Symposium on Nanotechnology in Construction, Paisley, Scotland, June 22-25, 2003. pp. 331-341.
Mathias, A. J. 2000. Environmental Benefits of Biomass Energy Projects. Paper Presented at Seminar on Environmental Impact of Developing Biomass Energy Projects for Power Generation/Cogeneration, Bangkok, Thailand, October $24-26,2000$

Nehdi, M. 2004. A reply to the discussion by A. Demirbas of the Paper "Performance of Rice Husk Ash Produced Using a New Technology as a Mineral Admixture in Concrete". Cement and Concrete Research. 34:1271-1272.

Oyetola, E. B. and Abdullahi, M. 2006. The Use of Rice Husk Ash in Low - Cost Sandcrete Block Production. Leonardo Electronic Journal of Practices and Technologies. 8: 58-70.

Saraswathy, V. and Song, Ha-Won. 2007. Corrosion Performance of Rice Husk Ash Blended Concrete. Construction and Building Materials. 21: 1779-1784.

Sata, V., Jaturapitakkul, C., and Kiattikomol, K. 2007. Influence of Pozzolan from Various by-Product Materials on Mechanical Properties of HighStrength Concrete. Construction and Building Materials. 21: 1589-1598.

Silva, F. G. da., Liborio, J. B. L., and Helene, P. 2008. Improvement of Physical and Chemical Properties of Concrete with Brazilian Silica Rice Husk (SRH). Revista Ingeniería de Construcción Journal. 23 (1): $18-25$.

Singh, N. B., Rai. S., and Chaturvedi, S. 2002. Hydration of Composite Cement. Progress in Crystal Growth and Characterization of Materials. 171-174.

Yu, Q., Sawayama, K., Sugita, S., Shoya, M. and Isojima, Y. 1999. The Reaction Between Rice Husk Ash and $\mathrm{Ca}(\mathrm{OH}) 2$ Solution and The Nature of Its Product. Cement and Concrete Research. $29: 37-43$.

Yu, X. and Kwon, E. 2009. A Carbon Nanotube/Cement Composite with Piezoresistive Properties. Smart Mater. Struct. 18 : 055010 (5pp).

Diterima : 30 Oktober 2008

Bakri

Lab. Keteknikan dan Diversifikasi Produk Hasil Hutan

Fakultas Kehutanan Universitas Hasanuddin

JI. Perintis Kemerdekaan Km. 10 Tamalanrea, Makassar 90245 